\section{PO-0088 HYPOTHALAMIC DISTURBANCES CAN MASK PITUITARY PATHOLOGIES: A CASE OF ADIPSIC CENTRAL DIABETES INSIPIDUS, GROWTH HORMONE DEFICIENCY AND HYPERPROLACTINAEMIA}

${ }^{1} \mathrm{R}$ Nicholls, ${ }^{1} Y$ Kumar, ${ }^{2} \mathrm{E}$ Crowne, ${ }^{2} \mathrm{C}$ Burren. ${ }^{1}$ Child Health, Royal Cornwall Hospital, Truro, UK; ${ }^{2}$ Paediatric Endocrinology, Bristol Royal Hospital for Children, Bristol, UK

10.1136/archdischild-2014-307384.757

Background This six year old girl unusually has central diabetes insipidus without polydipsia; with accompanying growth hormone deficiency and hyperprolactinaemia. She presented with 2 years of worsening breathlessness on minimal exertion, weight gain, poor linear growth and marked sweating in all weathers. Initial assessment revealed short stature (Height SDS-3.0), obesity (BMI 98th centile) and mild dehydration.

Methods Investigations demonstrated hypernatraemia (sodium $168 \mathrm{mmol} / \mathrm{L}$ ), hyperprolactinaemia (prolactin $3341 \mathrm{miu} / \mathrm{L}$ ), normal thyroid function and low Insulin-like growth factor-1. MRI pituitary demonstrated no microprolactinoma or other CNS lesion. Extremely low peak GH $0.5 \mathrm{ug} / \mathrm{L}$ (normal $>7 \mathrm{ug} / \mathrm{L}$ ) on Insulin tolerance testing indicated growth hormone $(\mathrm{GH})$ deficiency, but normal cortisols. Inpatient assessment demonstrated absence of thirst despite persisting hypernatraemia, high serum osmolality $(356 \mathrm{mOsmol} / \mathrm{kg})$, inappropriately dilute urine $(79 \mathrm{mOsmol} / \mathrm{kg})$ and urine output $4 \mathrm{ml} / \mathrm{kg} /$ hour. Low serum vasopressin $1.4 \mathrm{pmol} / \mathrm{L}$. Negative tumour markers.

Results GH replacement was extremely effective with improvement in height and normalisation of BMI. Managing her adipsic DI was challenging. Increasing oral intake of $1800 \mathrm{ml} /$ day was insufficient. DDAVP IM achieved urinary concentration (779 $\mathrm{mOsmol} / \mathrm{kg})$, but Oral DDAVP was ineffective, despite high daily dose 1000 ug. Normalisation of serum sodium and urine output was finally achieved with nasal DDAVP, although slight hyperosmolality persists. The patient has continued to experience excessive sweating. Serial MRIs continue to be normal.

Conclusion This unusual case of adipsic diabetes insipidus with excessive sweating is likely to represent hypothalamic dysfunction although no structural lesion is identified on MRI brain. Case series of adipsic diabetes insipidus have identified a high frequency of hypothalamic abnormalities associated with significant morbidity and mortality.

\section{PO-0089 SURVEY TO ASSESS INTEREST LEVEL OF PRESCHOOL CHILD'S PARENTS FOR PARTICIPATION IN A CLINICAL STUDY WHICH ASSESSES THE EFFECT OF NUTRITION INTERVENTION ON COGNITIVE MEASURES}

'S Nimbalkar, 'D Patel, ${ }^{2} \mathrm{AG}$ Phatak. 'Department of Pediatrics, Pramukhswami Medical College, Karamsad, India; ${ }^{2}$ Central Research Services, Charutar Arogya Mandal, Karamsad, India

\subsection{6/archdischild-2014-307384.758}

Background and aims Information on parent's willingness to participate in nutrition based studies based on randomization is scarce in literature. The aim of this survey was to assess the interest level of a pre-school child's parents for participation of their children in nutrition intervention study evaluating cognitive measures like memory.

Methods Parents were provided a questionnaire copy through their children studying in four kindergarten (KG) schools of
Anand District. Parents were required to sign the consent form, fill the questionnaire and send it back with their child to the school. A response was requested in five days but forms were collected even after 5 days by making repeated visits on three occasions to collect the forms. Descriptive analysis was done. The survey received approval from the Institutional Ethics committee and Principals of schools.

Results Total 1049 consent forms and questionnaires were distributed. From them 602 (57.39\%) were returned. However willingness to involve their children in nutritional based research for the duration of 6 months without blood pricks with understanding of randomization in intervention and control group was 180 (29.9\%). 41.5\% (250) did not respond and 28.6\% (172) did not want their child to participate.

Conclusion The interest level of a pre-school child's parents for participation of their children in nutrition intervention study evaluating cognitive measures like memory seems low. Providing more detailed information about the project may be an option to improve interest levels.

\section{PO-0090 DIFFERENT ASPECT OF PRECOCIOUS PUBERTY: CLINICAL EXPERIENCE AND OUTCOME (8 CASES)}

${ }^{1} \mathrm{M}$ Tfifha, ${ }^{1} \mathrm{D}$ Dhahri, ${ }^{1} \mathrm{H}$ Ajmi, ${ }^{1} \mathrm{~S}$ Mabrouk, ${ }^{2} \mathrm{~K}$ Kadri, ${ }^{1} \mathrm{~J}$ Chemli, ${ }^{1} \mathrm{~N}$ Zouari, ${ }^{1} \mathrm{~S}$ Hassayoun, ${ }^{2} \mathrm{~K}$ Tlili, ${ }^{1} \mathrm{~S}$ Abroug. ${ }^{1}$ Pediatrics, University Hospital Sahloul, Sousse, Tunisia; ${ }^{2}$ Radiology, University Hospital Sahloul, Sousse, Tunisia

\subsection{6/archdischild-2014-307384.759}

Background The term of precocious puberty signifies the onset of secondary sexual characters before the age of 9 years in the boys and 8 years in the girls. The first step in the clinical reflection is to decide whether the child has central or peripheral form of precocious puberty.

Objective Identify some causes of precocious puberty, expose difficulty of management.

Methods A retrospective study of medical records of children hospitalised in the Paediatric unit at Sahloul hospital in Tunisia.

Results Within a period of 6 years, eight patients were diagnosed with precocious puberty ( 4 boys and 4 girls). The mean age was 4 years and 3 months. The precocious puberty was isosexual in all cases with accelerated growth velocity. The PP was identify as central in four cases, the investigations showed: hypothalamic hamartoma (2 cases), pituitary adenoma (1 case) and arachnoid cyst (1 case). Peripheral precocious puberty included: congenital adrenal hyperplasia (3 cases) and adrenocortical carcinoma (1 case). The children with central precocious puberty were treated with gonadotrophin releasing hormone agonists, those with congenital adrenal hyperplasia received steroids replacement therapy and surgery was performed for the boy with adrenocortical carcinoma. The clinical and biological evolution of our patients was favourable with a regression of signs of puberty and normal hormone levels after a mean of 5 years.

Conclusion Precocious puberty needs a systematic approach with detailed history and clinical examination. Early treatment contributes to optimise adult height potential. There are still unresolved questions that future studies will need to address. Finally, the behavioural and psychological outcomes of precocious puberty were still poorly evaluated. 